\title{
Estimating Tunnel Strain in Weak and Schistose Rock Mass under a State of in-situ Stress Anisotropy
}

\author{
Pawan Kumar Shrestha and Krishna Kanta Panthi
}

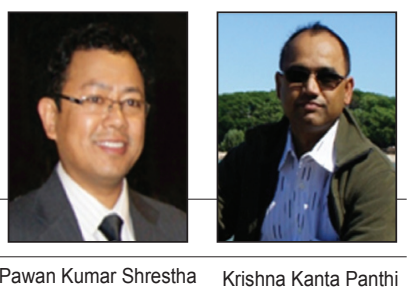

Abstract: Tunnels excavated in weak and schistose rock mass below high overburden (rock cover) are prone to instability in the form of tunnel deformation. The deformation in the tunnel takes place to such an extent that it is irreversible and of significant magnitude, which is often known as tunnel squeezing. In order to limit such plastic deformation in tunnels, it is desirable that the response of the rock mass to induced stresses is known so that requirement of rock support can be estimated. Contrary to the assumption of uniform in-situ stresses made in analytical solutions for elasto-plastic analyses, large degree of stress anisotropy condition prevails in most tunnelling conditions. The effect of such anisotropic stress condition leads to varying degrees of deformations around the tunnel contour. Therefore, stress anisotropy is also an important factor that needs to be addressed to ensure a proper support design for tunnels.

This paper discusses the inter-relationship among rock mass property, in-situ stresses including horizontal to vertical stress ratio, tunnel support pressure and deformation. The study is based on the tunnel cases from the Nepal Himalaya. Three completed tunnel projects were selected, where moderate to large tunnel deformations had been recorded. Long term deformation records were analyzed to assess time independent and time dependent deformations. Results of the analyses of the tunnels in weak and schistose rock mass at stress anisotropy states show that a good correlation among tunnel strain, rock mass shear modulus, support pressure, vertical stress and stress ratio of horizontal to vertical stresses exists. Moreover, the study also shows that significant amount of time dependent deformation can occur in such weak rock mass. Such deformation was found to be high in schist and micaceous phyllite, moderate in graphitic phyllite and low in siliceous phyllite. The suggested relationships can be used as a basis for an early estimate of instantaneous and final deformations and the corresponding requirement of support pressures in tunnel walls in weak and schistose rock mass.

Keywords: Tunnel, Schistose rock, Squeezing, Phyllite, Nepal

\section{Introduction}

Tunnels and underground structures are needed for 1 infrastructure development. However, stress and water induced instabilities are common challenges sin such underground structures. Tunnels obviously are favored to be placed in strong and homogeneous rock mass having low frequency of discontinuities and weakness zones. Strong rock mass have the capacity to withstand high rock stresses. However, it is not always possible to locate underground structures in strong rock mass and avoid weakness and faults zones, and particularly in the Himalayas where rock mass have undergone the effect of tectonic movement resulting in faulting, folding and shearing. High stresses in weak rock mass are among the major causes for plastic deformation in tunnels. Excessive deformation in the periphery of a tunnel eventually causes it to collapse. Weak and deformable rocks such as phyllite, schist, schistose gneiss and rock mass in weakness and fault zones are incapable of sustaining high tangential stress thereby resulting in squeezing of the tunnel section. Such phenomena are very common in the tectonically active Himalayan rock mass. Therefore, engineering principles and applications are pre-requisite to ensure safe and economic solutions of the problems.

Deformation in a tunnel is primarily dependent on rock mass property, in-situ stresses and rock support applied. Knowledge of the interaction among these parameters is of great importance for optimum rock support design and successful tunnel construction.
Various empirical (Singh et al., 1992; Goel et al., 1995), semi analytical (Hoek and Marinos, 2000) and analytical approaches (Carranza-Torres and Fairhurst, 2000; Panet, 2001; Carranza-Torres, 2004) and probabilistic approach of uncertainty analysis (Panthi, 2006; Panthi and Nilsen, 2007) to predict tunnel deformation under stress conditions in underground openings are practiced. However, a common limitation in most of the solutions is that stress anisotropy in non-circular tunnel has not been incorporated in the analyses. Whereas high degree of stress anisotropy exists in the Himalayan region; and cause of large plastic deformations in tunnels in this region may also be related to such high degree of stress anisotropy. Thus, this paper presents the plastic deformation behavior of the weak and schistose rock mass in tunnels under high degree of stress anisotropy. Selected projects for the analysis are Khimti 1 Hydropower Project, Kali Gandaki 'A' Hydroelectric Project and Middle Marsyanngdi Hydroelectric Project from the Nepal Himalaya.

\section{Plastic deformation in tunnels}

Deformation of tunnel is a response of rock mass to induced stresses around the tunnel opening whereas application of tunnel support offers resistance to further displacement of the rock mass. Importantly, such phenomenon is well noticeable in rock mass of weak and schistose character having low to medium strength, deformable or particulate in nature. In 
such rock mass, the deformation of tunnel takes place to such an extent that it is irreversible and of significant magnitude. Such deformation in tunnels is defined as plastic deformation. Irrespective of its magnitude, deformation in tunnel can be categorically distinguished as an instantaneous deformation and a long term deformation. Generally, the first observation in tunnel will be the instantaneous response of the rock mass upon opening of the tunnel. Such an effect is assumed to reach at its maximum state when the effect of tunnel face as a fictitious support is ceased. Rock support interaction that includes such instantaneous response of the rock mass at this early stage of tunnel excavation to induced stresses is the basic approach adopted in tunnel support design. It is also noticed that tunnels in weak and schistose rocks continue to deform as time advances. Total deformations in tunnels at long term are thus inclusive of instantaneous and time dependent deformations.

\section{Instantaneous deformation}

Assessment of tunnel displacement and stresses around it can be readily evaluated by using close form solutions. Various analytical solutions of elasto-plastic behavior of homogeneous rock mass in a circular tunnel in a plane strain condition and in isostatic stress environment are available (Hoek and Brown, 1980; Detournay and Fairhurst, 1987; Carranza-Torres and Fairhurst, 1999; Carranza-Torres, 2004; Sharan, 2003 and 2005; Alejano et al., 2009) and an appropriate one should be chosen according to stress-strain behavior of the rock mass. Basic principle in the elasto-plastic solutions is that, when internal pressure (pi) at the tunnel contour is less than the initial in-situ stress value so, the tunnel wall converges. If the internal pressure (pi) falls below critical support pressure (picr), then failure of the rock mass surrounding the tunnel occur thereby forming a plastic region of radius Rpl around it (Figure 1). Extent of such plastic region varies according to the stress-strain behavior of the rock mass.

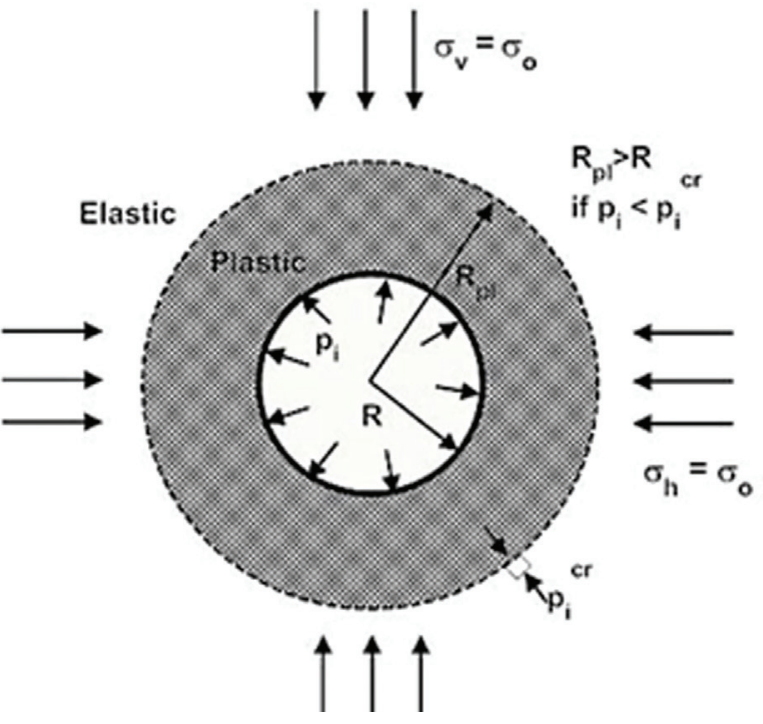

Figure 1: Elasto-plastic regions around a circular tunnel (after Carranza-Torres, 2004)
Analytical solutions are simplified and also consider assumptions, among which two important assumptions that can vary in real tunneling cases. First, the in-situ stresses are assumed uniform all around the tunnel with a single value of so; and the second is that the tunnel is circular in shape. In reality, both of these assumptions may or may not be the case.

In-situ stresses around tunnels located at depth vary according to overburden and tectonic contribution in the stress. Stress measurements show that vertical stress (sv) in $\mathrm{MPa}$ is approximately 0.027 times the overburden depth measured in meter, which is the specific weight of common rock material. In contrary, estimation of horizontal stress is a fairly complex procedure. The horizontal stress is composed of gravity-led horizontal stress (sh) and component of tectonic stress (stec), as presented in Equation (1) (Panthi, 2012). The gravity-led horizontal stress is attributed to the effect of Poisson's ratio (v) together with the vertical stress. When the Poisson's ratio (v) of rock is low, e.g. 0.10 in schistose and thinly foliated rocks (Panthi, 2006), the gravity-led horizontal stress becomes merely close to $10 \%$ of the vertical stress. On the other hand, estimation of the tectonic stress is a difficult task unless it is back calculated or directly measured.

$$
\sigma_{h}=\frac{v}{1-v} \sigma_{v}+\sigma_{t e c}
$$

Tectonic stresses vary according to the extent of tectonic movement, its movement direction and degree of schistosity and shearing. Based on the measured horizontal stresses in the Nepal Himalaya (Nepal, 1999), tectonic stress magnitude varies between 3 and $4 \mathrm{MPa}$ if rock mass is schistose and sheared. According to Panthi (2012), the orientation of the tectonic stress in the central part of the Himalaya is very close to North-South. Thus, tunnels oriented North-South will have least effect of the tectonic stress across its section. Under such circumstance, the total in-plane horizontal stress in a tunnel at high depth can be relatively low, resulting to high degree of stress anisotropy. And, under stress anisotropy around the tunnel opening, magnitude and uniformity of displacements estimated by elasto-plastic analyses will thus vary greatly. There have been limited solutions to address stress anisotropy in tunnel. Kirsch solution can be a useful tool in the state of stress anisotropy, but its validity in elastic medium only may result to lower degree of displacement in the tunnels. Detournay and John (1988) presenting design charts for deep circular tunnels under non-uniform loading condition stated that, as deviatoric stress increase the failure region around an unsupported tunnel will be like a butterfly shape. Pan and Chen (1990) and Carranza-Torres and Fairhurst (2000) also made similar conclusion for tunnels at high degree of stress anisotropy. CarranzaTorres and Fairhurst (2000) further stressed that elasto-plastic numerical analyses should be carried out at high stress anisotropy case when the stress ratio $(\mathrm{k})$ is less than 0.6. 
Another important aspect in the tunnel design is shape of the opening. Not all tunnels are excavated in circular shape; particularly drill and blast tunnels are excavated in horseshoe or inverted-D in shape. Unlike circular tunnel, tunnels in these shapes will have relative stress concentration and distressing around the tunnel periphery. Limited analyses and approaches to estimate displacement in tunnels having shape other than circular lead to requirement of numerical modelling.

\section{Long term deformation}

Whereas the instantaneous deformation in tunnel is a result of yielding of rock mass due to tunnel excavation progress and stress redistribution around it, long term deformation in tunnel is further enhanced by the creep effect. Creep has a significant effect in time dependent deformation of rock mass which may occur under long term exposure to a constant load subjected to the rock mass. It is essentially a time dependent behavior of rock mass where strain increases without increment of stress on the rock mass. Time dependent behaviors can be modeled either by simulating creep characteristics of the rock mass in rheological models or by empirical methods. If laboratory data of the creep characteristics are available, tunnel creep curves can be fitted. Despite the fact that simple to advanced creep models are simulated in numerical modeling, representation of rock mass creep properties is always an important issue. Whereas in-situ creep tests are rarely conducted, creep properties of rock mass as input parameters in simplified analytical or in numerical modeling are often based on limited laboratory data. Therefore, reliability in estimation of time dependent deformation in tunnels depends on the accuracy of creep input parameters.

Closures in tunnels can be expressed as a function of distance to the tunnel face and time of excavation. Sulem et al. (1987) presented a curve fitting technique in order to determine total tunnel displacement based on such information. Accordingly, convergence $(\mathrm{C}(\mathrm{x}, \mathrm{t}))$ at distance $\mathrm{x}$ in meter from the tunnel face and $t$ days from the time of tunnel excavation can be estimated using Equation (2).

$$
C_{(x, t)}=C_{\infty x}\left[1-\left(\frac{X}{x+X}\right)^{2}\right]\left[1+m\left\{1-\left(\frac{T}{t+T}\right)^{n}\right\}\right]
$$

Here, $\mathrm{X}$ is a length related to the distance of influence of the tunnel face, $\mathrm{T}$ is a characteristic parameter of the time dependent properties of the ground, Cox is an instantaneous closure as obtained in the case of an infinite rate of face advance, $\mathrm{m}$ represents increment of instantaneous deformation due to effect of rheology, and $\mathrm{n}$ is a constant normally taken as 0.3 .

This equation is very much practiced in predicting tunnel deformation, back calculating lost displacement and in estimation of time independent and dependent tunnel displacements. The significance of the above equations lies in the fact that the time dependent deformation and the final closure in tunnel can be estimated based on convergences actually measured with respect to distance to tunnel face and time of excavation. This procedure can ensure reliable prediction of long term displacement in tunnels than by simplified analytical solutions that are based on limited laboratory data of creep characteristics of rock mass.

Alternatively, potentiality and estimation of large tunnel deformation (often known as squeezing) in weak rocks can also be done using empirical and semi-analytical methods. At an early stage of tunnel design when there is little information available, squeezing can be estimated using empirical relations like those proposed by Singh et al. (1992) and Goel et al. (1995). The limitation of these suggestions is that the magnitude of potential tunnel deformation cannot be estimated. Hoek and Marinos (2000) showed that tunnel strain can be related to ratio of rock mass strength and vertical stress. Advantage of the Hoek and Marinos approach is that, the relationship can be used to first-estimate potentiality of squeezing in weak rocks at depth. The relationship is relatively simple, requiring only the rock mass strength and support pressure as input and the vertical stress can be computed using rock cover and specific weight of the overlying rock mass, yet this method does not address stability of tunnels in stress anisotropy conditions.

\section{Tunnel failure in stress anisotropy condition}

When horizontal to vertical stress ratio (k) is close to unity or where the deviatoric stress (sv - sh) is less, the failure zones around the tunnels are elliptical. Such shapes, as examples of FLAC3D (Itasca, 2009) numerical modeling of four tunnel cases from Khimti headrace tunnel conducted by Shrestha and Panthi (2014a), are shown in Figure 2 (a), (b) and (d). Similarly, the tunnel section having the lowest stress ratio (k) has higher deformation in the walls. At such high anisotropic stress situation, plastic region around the tunnel becomes a butterfly-like shape as shown in Figure 2 (c). These results are similar to those presented by Detournay and John (1988) and as discussed by Carranza-Torres and Fairhurst (2000). These analyses show that deterioration of weak rock mass around tunnel under high anisotropic in-situ stresses are observed to be high around tunnel walls and inverts compared to the crown, therefore estimation of support requirement should be made accordingly.

\section{Estimation of tunnel strain and support requirement}

When rock mass around a tunnel opening is subjected to induced stresses, behavior of the rock mass that undergoes deformation is a matter of interest towards support design. One of the important rock mass properties that exhibit rock mass deformation is shear modulus (G) of the rock mass. The shear modulus (G) can be estimated from deformation modulus (Erm) and Poisson's Ratio ( $v$ ) of the rock mass. Response of the rock mass thus can be correlated with the shear 
modulus (G), in-situ stresses represented by vertical stress (sv) and ratio $(\mathrm{k})$ of horizontal stress to the vertical stress and applied support pressure (pi). support pressure and the power function constants at tunnel spring level are presented in Equations (4) and (5).

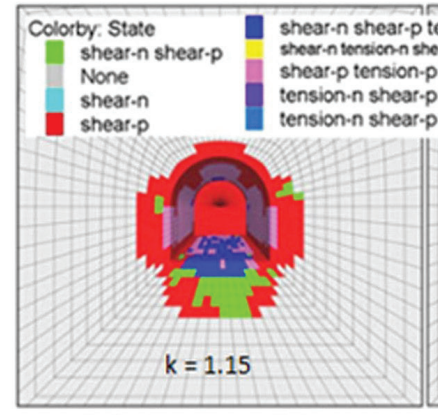

(a) Chainage $607 \mathrm{~m}$

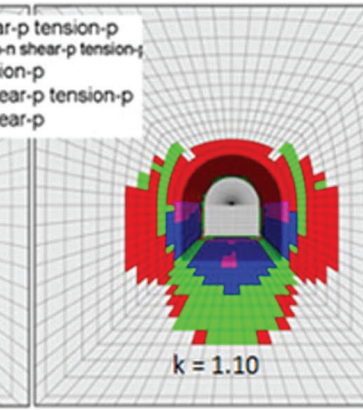

(b) Chainage $712 \mathrm{~m}$

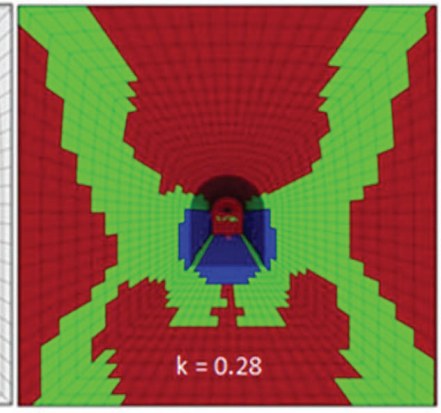

(c) Chainage $5191 \mathrm{~m}$

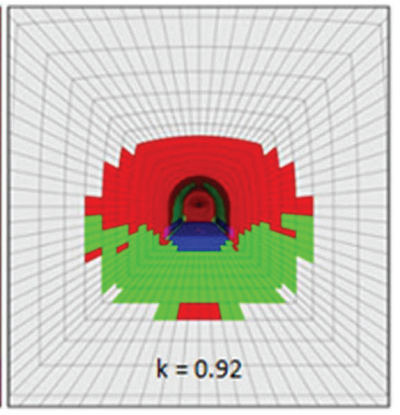

(d) Chainage $6727 \mathrm{~m}$

Figure 2: Plastic regions around the Khimti tunnels (Shrestha and Panthi, 2014a)

Analytical and numerical analyses performed by Shrestha and Panthi (2014b) using recorded deformations (or tunnel strain) at 77 different sections of Kali Gandaki headrace tunnel showed that there is a good correlation among these parameters. First, a relationship was formulated from the results of analytical elasto-plastic analyses of the tunnel sections that had more than $2 \%$ tunnel strain. A power function was established between tunnel strain $(\varepsilon)$ and the ratio of shear modulus (G) and in-situ vertical stress (sv) in which the constants of the function could be estimated for any value of support pressure (pi). On this basis, it was envisaged that a similar relationship could also be established in an anisotropic stress environment. Numerical analyses using FLAC3D on selected 12 tunnel sections of inverted-D in shape at actual stress ratios ranging from 0.22 to 0.38 revealed that tunnels in such non-uniform stress environment would have lesser degree of deformation compared to that in isostatic vertical stress conditions. It was also observed that the tunnel crown would have rather closer deformation to those considering average of vertical and horizontal stress condition. On the other hand, the tunnel walls would have deformation values in-between the average in-situ stress and isostatic vertical stress conditions. The relationship formulated for the analytical solution could thus be updated with the effect of stress anisotropy represented by stress ratio (k) and is presented as Equation (3). The constants of the power function can be computed for any support pressure value (pi). Relationship of

$$
\begin{gathered}
\varepsilon_{s p l}=a_{s p l}\left(\frac{2 G}{\sigma_{v}(1+k) / 2}\right)^{b_{s p l}} \text { (3) } \\
a_{s p l}=742.23 p_{i}{ }^{2}-1870.6 p_{i}+1654.7 \\
b_{s p l}=-0.1541 p_{i}{ }^{2}+0.2022 p_{i}-2.0003
\end{gathered}
$$

The above equations estimate total strain (deformation) in tunnel, and the support pressure corresponds to final support required to contain the tunnel strain within the estimated range. It is however to be noted that, prime concern at the time of tunnel excavation will obviously be immediate stability of the tunnel. But as the tunnel progresses, weak and schistose rock continues to deform generating extra pressure on applied support. Therefore, tunnel support should be designed in such a way that the immediate requirement of support pressure and the support pressure that corresponds to future possible tunnel deformation are also addressed.

If longitudinal tunnel deformation records with respect to distance to tunnel face (x) and time of excavation (t) are available, it may be possible to estimate such future tunnel deformation. The curve fitting Equation (2) proposed by Sulem et al. (1987) is a useful tool in this endeavor. This equation can be used in particular in estimating instantaneous closure $(\mathrm{CoOx})$ in tunnels and final closure (FC). Here, the final closure can be estimated as $\mathrm{C} \infty \mathrm{x}(1+\mathrm{m})$. Further, the equation also categorically distinguishes time independent and dependent deformations in tunnels.
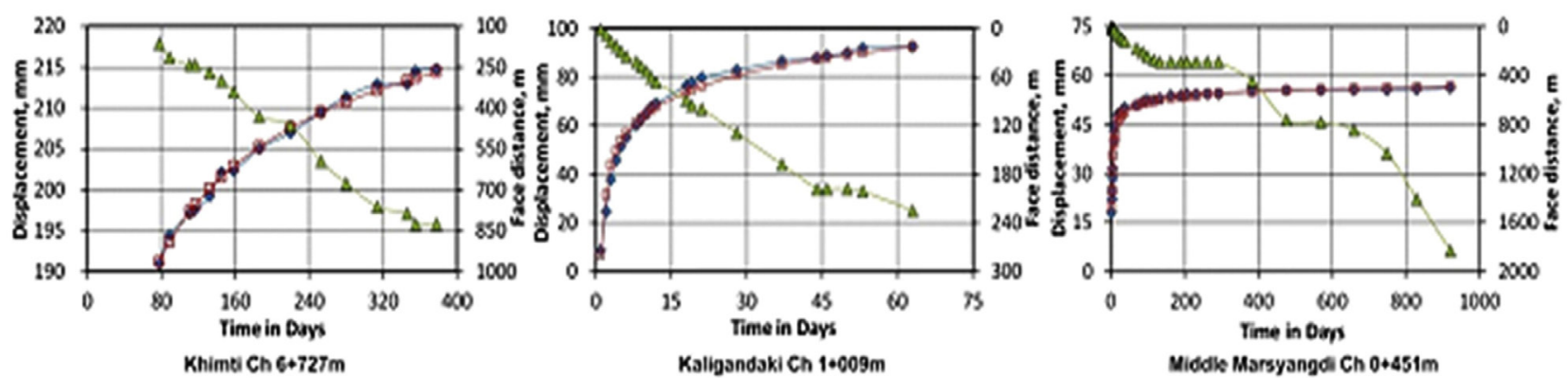

Figure 3: Measured and computed deformations in Khimti, Kali Gandaki ' $A$ ' and Middle Marsyangdi headrace tunnels 
Accordingly, Shrestha and Panthi (2014c) evaluated long term deformations of 24 tunnel sections in four different rock mass conditions from three tunnel projects (Khimti, Kali Gandaki and Middle Marsyangdi Hydroelectric Projects) and computed instantaneous and final closures determining time independent and dependent variables. Deformation parameters Cax, $\mathrm{m}$, T and $\mathrm{X}$ were fitted in the Equation (2) in such a way that sum of square of errors between measured and computed tunnel deformation was the least. Typical charts of measured and computed tunnel deformations with respect to time of excavation and distance from tunnel face for each of the tunnel projects are presented in Figure 3.

Evaluating the instantaneous and final closures with respect to rock mass shear modulus (G), support pressure (pi), vertical stress (sv), and horizontal to vertical stress ratio $(\mathrm{k})$ for each of the tunnel cases, a simplified single relationship among these four parameters are established. Here, the support pressure is incorporated as numerator in the ratio of shear modulus and vertical stress and stress ratio. Relationships for instantaneous and final strain are based on the trend lines having goodness of fit as shown in Figure 4, and are presented as Equations(6) and (7).

$$
\begin{aligned}
& \varepsilon_{F C}=4509\left(\frac{2 G\left(1+p_{i}\right)}{\sigma_{v}(1+k) / 2}\right)^{-2.09} \\
& \varepsilon_{I C}=3065\left(\frac{2 G\left(1+p_{i}\right)}{\sigma_{v}(1+k) / 2}\right)^{-2.13}
\end{aligned}
$$

Usefulness of these equations also lies in the fact that an initial and permanent support requirement can be estimated using these equations. Requirement of additional support over initially applied support can be estimated if long term time dependent tunnel strain as $\left(\varepsilon_{F C}-\varepsilon_{I C}\right)$ can be estimated. Component of such time dependent tunnel deformation in total tunnel deformation varies according to rock mass type. As shown in Figure 5, general trend indicates that such time dependent effect is high in schist and schistose mica gneiss; whereas augen mica gneissic rock mass are little affected. Similarly, micaceous phyllite rock mass have high time dependent deformation compared to siliceous phyllite rock mass containing quartzite as intercalation. Moreover, graphitic rock mass will have moderate effect of time in tunnel deformation. It is noted here that Khimti headrace tunnel has schist and schistose mica gneiss, Kali Gandaki heading tunnel has graphitic phyllite and full face tunnel has siliceous phyllite and Middle Marsyangdi tunnel has siliceous to micaceous phyllite rock mass. These results also signify that composition of rock minerals do affect the deformation characteristics of the rock mass. Presence of quartz or silica minerals contributes to lesser deformation while mica rich rock mass experience larger deformation.

\section{Conclusions}

Rock mass quality plays an important role in tunnel stability. Common characteristics of the rock mass in the studied tunnel cases from the Nepal Himalaya are that the rock mass are schistose, deformed, weak and have low strength, low degree of rigidity against deformation and high degree of strength anisotropy. Tunnels in such rock mass when exposed to high degree of in-situ stresses are prone to plastic deformation. Such plastic deformations in tunnels can occur at the time of excavation and later. In order to ensure a stable tunnel, understanding the mutual relationship among rock mass mass property, support pressure and in-situ stress (Shrestha and Panthi, 2014c)

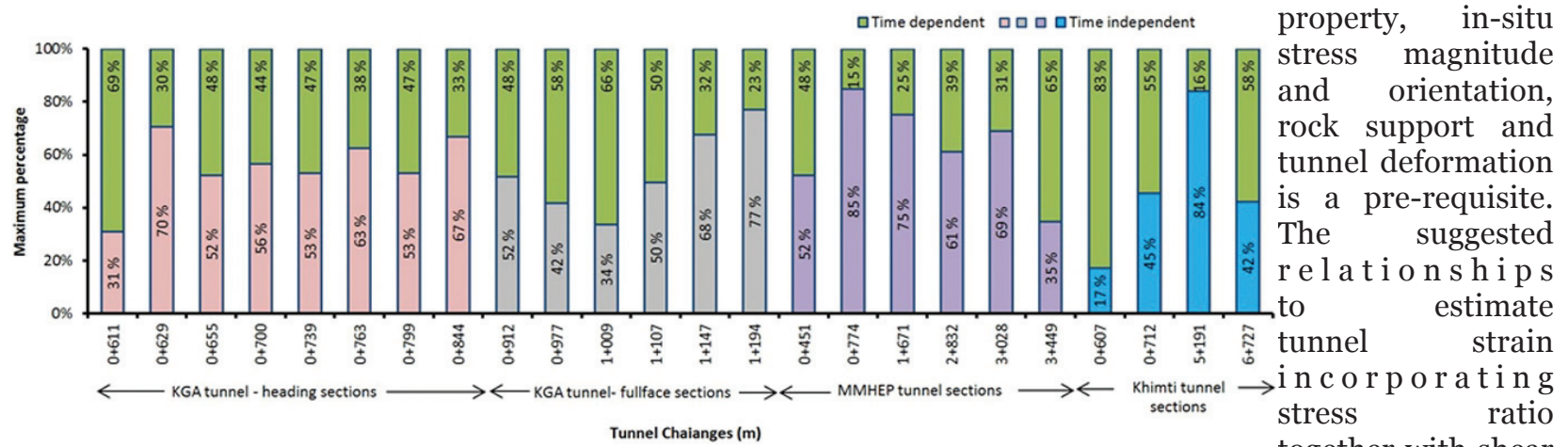

Figure 5: Maximum percentage of time independent and dependent deformations (Shrestha and Panthi, 2014c) together with shear 
modulus, support pressure and vertical stress can be a basis for an early estimate of tunnel deformation in weak to medium strong and schistose rock mass.

However, as indicated in Figure 4, the relative goodness of fit of the instantaneous strain compared to the final strain is slightly low, and therefore, some deviation in the instantaneous strain can be expected. In homogeneity of rock mass can also have varying degree of tunnel deformation. Moreover, the relationships suggested are based on the trend lines of results of numerical modeling and analytical method. Therefore, some degree of deviation can be expected in estimation of tunnel strain. Further, the analyses have been done for deformation in the tunnel walls only, which happened to be the largest deformation recorded in most of the tunnel sections. Estimation of strain at tunnel wall only can be one of the major limitations of the suggested procedure.

Pawan Kumar Shrestha holds PhD in Rock Engineering and MSc in Hydropower Development from Norwegian University of Science and Technology. He has more than 15 years of experience in planning, design and construction of hydropower schemes and underground structures in Nepal.

\section{Email:pawan304@gmail.com}

Krishna Kanta Panthi holds PhD in Rock Engineering and MSc in Hydropower Development. He works as Associate Professor of Geological engineering at the Department of Geology and Mineral Resources Engineering, Norwegian University of Science and Technology (NTNU), Norway. He has over 22 years of experience in tunneling, hydropower planning and design, construction management and mining technologies.

Corresponding address: krishna.panthi@ntnu.no

\section{References}

Alejano, L. R., Rodriguez-Dono, A., Alonso, E., and Fernandez-Manin, G. (2009). Ground reaction curves for tunnels excavated in different quality rock masses showing several types of post-failure behavior. Tunnelling and Underground Space Technology, vol. 24(6), pp. 689-705.

Carranza-Torres, C. (2004). Elasto-plastic solution of tunnel problems using the generalized form of the Hoek-Brown failure criterion. International Journal of Rock Mechanics and Mining Sciences, vol. 41(3), pp. 480-481.

Carranza-Torres, C. and Fairhurst, C. (1999). The elasto-plastic response of underground excavations in rock masses that satisfy the Hoek-Brown failure criterion. International Journal of Rock Mechanics and Mining Sciences, vol. 36(6), pp. 777-809.

Carranza-Torres, C. and Fairhurst, C. (2000).
Application of the convergence-confinement method of tunnel design to rock-masses that satisfy the Hoek-Brown failure criterion. Tunnelling and Underground Space Technology, vol. 15(2), pp. 187-213.

Detournay, E. and Fairhurst, C. (1987). TwoDimensional Elasto-plastic Analysis of a Long, Cylindrical Cavity under Non-Hydrostatic Loading. International Journal of Rock Mechanics and Mining Sciences and Geomechanics, vol. 24(4), pp. 197-211.

Detournay, E. and John, C.M.S. (1988). Design charts for a deep circular tunnel under non-uniform loading. Rock Mechanics and Rock Engineering, vol. 21(2), pp. 119-137.

Goel, R. K., Jethwa J. L., and Paithankar, A.G. (1995). Indian experience with $\mathrm{Q}$ and RMR systems. Tunnelling and Underground Space Technology, vol. 10, pp. 97-109.

Hoek, E. and Brown, E. T. (1980). Underground Excavations in Rock. Institute of Mining and Metallurgy, London.

Hoek, E. and Marinos, P. (2000). Predicting Tunnel Squeezing Problems in Weak and Heterogeneous Rockmasses. Tunnels and Tunnelling International, vol. 32(11), pp. 34-46 and vol. 32(11), pp. 45-51.

Itasca Inc. (2009). FLAC3D User's Manual. http:// www.itascacg.com

Nepal, K. M. (1999). A review of in-situ testing of rock mechanical parameters in hydropower projects of Nepal. Journal of Nepal Geological Society, vol. 19, pp. 1-8

Pan, Y. W. and Chen, Y. M. (1990). Plastic zones and characteristics-line families for openings in elastoplastic rock mass. Rock Mechanics and Rock Engineering, vol. 23(4), pp. 275-292.

Panet, M. (2001). Recommendations on the convergence confinement method. Association Francaise des Travaux en Souterrain (AFTES), Paris, pp. 1-11.

Panthi, K. K. (2006). Analysis of Engineering Geological Uncertainties Analysis Related to Tunnelling in Himalayan Rock Mass Conditions. (Doctoral Thesis at NTNU 2006:41). Department of Geology and Mineral Resources Engineering, Norwegian University of Science and Technology, Norway

Panthi, K. K. (2012). Evaluation of rock bursting phenomena in a tunnel in the Himalayas. Bulletin of Engineering Geology and the Environment, vol. 71, pp. 761-769

Panthi, K. K and Nilsen, B. (2007). Uncertainty analysis of tunnel squeezing for two tunnel cases from Nepal Himalaya. International Journal of Rock Mechanics and Mining Sciences, vol. 44, pp. 67-76. 
Sharan, S. K. (2003). Elastic-brittle-plastic analysis of circular openings in Hoek-Brown media. International Journal of Rock Mechanics and Mining Sciences, vol. 40(6), pp. 817-824.

Sharan, S. K. (2005). Exact and approximate solutions for displacements around circular openings in elastic-brittle-plastic Hoek-Brown rock. International Journal of Rock Mechanics and Mining Sciences, vol. 42(4), pp. 542-549.

Shrestha, P. K. and Panthi, K. K. (2014a). Analysis of plastic deformation behavior of schist and schistose mica gneiss at Khimti headrace tunnel, Nepal. Bulletin of Engineering Geology and the Environment, vol. 73, pp. 759-773.

Shrestha, P. K. and Panthi, K. K. (2014b). Assessment of the effect of stress anisotropy on tunnel deformation in the Kali Gandaki Project in the Nepal Himalaya. Bulletin of Engineering Geology and the Environment. Published online 15 July 2014, DOI 10.1007/s10064-014-0641-5.

Shrestha, P. K. and Panthi, K. K. (2014c). Predicting plastic deformation in tunnels-an analysis based on tunnel cases from the Nepal Himalaya. Rock Mechanics and Rock Engineering. Under review.

Singh, B., Jethwa J. L., Dube A. K., and Singh B. (1992). Correlation between observed support pressure and rock mass quality. Tunnelling and Underground Space Technology, vol. 7, pp. 59-74.

Sulem, J., Panet, M., and Guenot, A. (1987). Closure Analysis in Deep Tunnels. International Journal of Rock Mechanics and Mining Sciences and Geomechanics, vol. 24(3), pp. 145-154.

\section{CALENDER OF EVENTS - WATER}

12-17 April 2015, 7th World Water Forum 2015, Location: Daegu EXCO, Gyeonqiu HICO, URL:

http://www.hydropower-dams.com/other-eventscalendar.php?c_id $=156$

o9 April 2015 1st International Seminar on Algal Technologies for Wastewater Treatment and Resource Recovery, Location: UNESCO- IHE,

\section{HYDROPOWER AND DAMS}

17-19 February 2015, 2015 Annual Conference, Location: Portland Marriott Downtown Waterfront Hotel Portland, OR, Location: http://www.nwhydro.org/ events_committees/calendar_events.htm

7-8 May 2015 Technical Seminar, Location: Hood River, Oregon, URL: http://www.nwhydro.org/events_ committees/calendar_events.htm

18-20 May 2016 Transamerica Expo Center, Location: Sao Paulo, Brasil, URL: http://www.powerbrasilevents. com/en/event-info/schedule-of-events.html

13-20 June 2015 ICOLD Annual Meeting and Congress, Location: Stavanger, Norway. http://www. hydropower-dams.com/other-events-calendar. php?c_id=156

\section{RENEWABLE ENERGY}

4-5 February 2015, 7th Annual Solar Power Generation USA Congress, Location: Marriott Mission Valley, San Die, CA, URL: http://www.greenpowerconferences. com/home/allevents?search_product=Conference

9-10 February 2015 4th Annual International Conference on Sustainable Energy and Environment Sciences (SEES 2015), Location: Singapore, URL: http:// www.env-energy.org/

25-27 February 2015 World Sustainable Energy Days, Location: Wels/Austria. URL: http://www.wsed.at/ en/world-sustainable-energy-days/

14th July 2015 Hydro vision Workshop New Hydro Development, Location: Portland Convention Center, Portland, Oregon, URL: http://www.nwhydro.org/ events_committees/calendar_events.htm

24-25 September 2015, the 7th International Symposium on Roller Compacted Concrete (RCC) Dams, Location: Chengdu City, China, http://www.hydropowerdams.com/other-events-calendar.php?c_id $=156$

26-28 October 2015, International Conference and Exhibition will take Place at the Cordeaux Convention Centre, France, URL: http://www.hydropowerdams.com/hydro-2015.php?c_id=88

25-27 March 2015, Solar Power Generation Central America, Location: Intercontinental Playa Bonita and Spa Panama, URL: http:// www.greenpowerconferences.com/home/ allevents? search_product $=$ Conference

19-20 May 2015, Mexican International Renewable Energy Congress, Mexico's Leading Renewable Energy Event, Location: Mexico City, Mexico, URL: http://www.greenpowerconferences.com/home/ allevents?search_product=Conference 